Gender Differences in Academic Surgery Work-Life Balance and Satisfaction

Short title: gender differences in academic surgery

Dadrie Baptiste, $M D^{1}$, Alison M Fecher, $M D^{1,2}$, Scott C Dolejs, $M D^{1,2}$, Joseph Yoder, $\mathrm{MS}^{2}, \mathrm{C}$ Maximillian Schmidt, MD, PhD, MBA ${ }^{1}$, Marion E Couch, MD, PhD, MBA ${ }^{3}$, DuyKhanh P Ceppa, MD ${ }^{1,2}$

${ }^{1}$ Department of Surgery, ${ }^{2}$ Center for Outcomes Research in Surgery, ${ }^{3}$ Department of Otolaryngology, Head \& Neck Surgery; Indiana University School of Medicine, Indianapolis, IN, USA.

Presented at the 12th Annual Academic Surgical Congress, Las Vegas, NV February 79, 2017.

Corresponding author:

DuyKhanh P Ceppa, MD

Assistant Professor of Surgery

Division of Cardiothoracic Surgery, Department of Surgery

Indiana University School of Medicine

545 Barnhill Drive, EH 215

Indianapolis, IN 46220

dpceppa@iupui.edu

317.944 .7728

Author contribution:

Study conception and design: Baptiste, Ceppa, Fecher

Acquisition of data: Baptiste, Ceppa

Analysis and interpretation of data: Baptiste, Ceppa, Dolejs, Yoder

Drafting of manuscript: Baptiste, Ceppa, Dolejs

Critical Revision: Couch, Schmidt 
Abstract

Background

An increasing number of women are pursuing a career in surgery. Concurrently, the percentage of surgeons in dual-profession partnerships is increasing. We sought to evaluate the gender differences in professional advancement, work-life balance and satisfaction at a large academic center.

Materials and methods

All surgical trainees and faculty at a single academic medical center were surveyed. Collected variables included gender, academic rank, marital status, family size, division of household responsibilities, and career satisfaction. Student's t-tests, Fisher's exact, and Chi-square were used to compare results.

Results

There were 127 faculty and 116 trainee respondents (>80\% response rate).

Respondents were mostly male ( $77 \%$ of faculty, $58 \%$ of trainees). Women were more likely than men to be married to a professional ( $90 \%$ vs. $37 \%$, for faculty; $82 \%$ vs. $41 \%$ for trainees, $p<0.001$ for both) who was working full time $(p<0.001)$ and were less likely to be on tenure track $(p=0.002)$. Women faculty were more likely to be primarily responsible for child care planning $(p<0.001)$, meal planning $(p<0.001)$, grocery shopping $(p<0.001)$, and vacation planning $(p=0.003)$. Gender neutral responsibilities included financial planning $(p=0.04)$ and monthly bill payment $(p=0.03)$. Gender differences in division of household responsibilities were similar in surgical trainees except for child care planning, which was a shared responsibility. Conclusion 
Women surgeons are more likely to be partnered with a full-time working spouse and to be primarily responsible for managing their households. Additional consideration for improvement in recruitment and retention strategies for surgeons might address barriers to equalizing these gender disparities.

Abstract word count: 248

Key words: academic surgery, work-life balance, gender 
Introduction

Over the last several decades there has been a steady rise in the number of females in the medical profession. According to the AAMC the graduating class of 2016 was 49.8\% female and $50.2 \%$ male $^{1}$. Although the percentage of females pursuing surgical careers is not as robust, it, too, has seen a steady rise over the years ${ }^{2}$. Concomitantly, there has been a rise in dual physician relationships. Goodman, et al reported that physicians were more likely to marry other physicians or those with a higher degree of learning than previously ${ }^{3}$. In 2010, $54 \%$ of physicians were married to another professional, as opposed to less than 10\% in 1960.

Dual professional/dual physician relationships create a unique set of challenges in both the professional and personal environments. Work-home conflicts have been previously described as being a factor in surgeon burn-out and depression 4 . Moreover, prior studies have reported household responsibilities to primarily be the concern of women surgeons despite being in dual professional partnerships ${ }^{4-6}$. We sought to further delineate the gender differences in professional advancement, work-life balance, division of household duties, and overall career satisfaction amongst surgical trainees and faculty at a major academic center.

Methods 
All surgical trainees (residents, clinical fellows) and faculty in the Departments of Surgery (including the Divisions of Abdominal Transplant, Colorectal, Cardiothoracic, Minimally-invasive, Pediatric, Plastic, Surgical Oncology, Trauma, and Vascular Surgery), Neurosurgery, Ophthalmology, Orthopedic Surgery, Otolaryngology, and Urology at a single, large academic medical center were included in the study. Approval from our institution's Internal Review Board was obtained prior to study initiation.

\section{Survey instrument}

A pilot survey was administered to faculty members and residents of the Division of General Surgery in August 2015. The survey was then revised to improve the user interface. The survey was designed to acquire data in the following areas: gender, specialty, surgical training, academic rank, academic productivity, marital status, spouse employment status, spouse profession, family size, division of household responsibilities, and career satisfaction. The study was designed for ease of the respondent, with few open-ended questions. Satisfaction scores were measured on a Likert-like scale. A priori categories were created for years in practice (0-5 years; 6-10 years; $11-15$ years; and $>15$ years) and number of publications. Spousal level of employment was defined as a homemaker if the spouse did not work; part time if the spouse worked less than 1 full-time equivalent (FTE); and full time if the spouse worked 1 FTE.

A final version of the survey (Appendix 1, Survey Monkey, Inc. ${ }^{7}$ ) was distributed via email to all potential participants in January 2016. Subjects were identified through 
department listservs. The completion of the survey was considered implied consent to participate in the study. A reminder noticed was issued two and three weeks later. The survey was closed for collection of responses 30-days following initial distribution.

\section{Statistical analysis}

Univariate data analysis was performed for categorical variables with Fisher's exact and Chi-square tests as appropriate. Continuous data was assessed for normality. The Likert scales were normal, and parametric tests (non-paired T-tests) were used to assess the Likert scales. Using parametric test in survey responses that utilize a Likert scale is well established in the current literature ${ }^{8}$. The number of publications exhibited substantial deviation from a normal distribution. Thus, this variable was studied with a Wilcoxon rank-sum test. Interaction between years in practice and gender was tested for various outcomes including: the number of publications, academic rank, academic track, marital status, and satisfaction scores. For categorical outcomes with more than two levels, a multivariable multinomial distribution was used to assess for interaction. For categorical outcomes with two levels, Breslow-Day test was used. For numerical outcomes, multivariable linear regression was used. All statistical analysis was performed using SAS version 9.4 (Cary, NC).

Results

Respondent demographics

The survey was distributed to 156 faculty surgeons and 121 clinical trainees (residents and fellows). One hundred and twenty-seven faculty (81\%) and 116 trainees (96\%) 
responded, with more than $90 \%$ of respondents answering all pertinent questions. Table 1 depicts the demographics of the survey respondents. The respondents were predominantly male $(77 \%$ of faculty and $58 \%$ of trainees, $\mathrm{p}=0.002)$ and married or in committed relationships ( $87 \%$ of faculty and $66 \%$ of trainees, $p=<0.001$ ). The majority of participants were in the Department of General Surgery (56\% of faculty, $65 \%$ of trainees). Ninety-five percent of faculty were fellowship-trained, and $80 \%$ of trainees indicated that they intend to pursue fellowship training. Faculty were more likely than trainees to be married ( $87 \%$ vs. $66 \%, p<0.001)$ and were more likely to have children (87\% vs. $27 \%, p<0.001)$.

\section{Employment level and academic advancement}

Women were more likely to be more junior than men ( $p=0.05$; Table 2$)$. There was no significant difference in the level of employment $(p=0.4)$ between men and women. Male faculty were more likely to have published ( $99 \%$ vs. $76 \%, p<0.001)$, with male faculty having more publications (median 21 vs. $6, p<0.001$ ). However, after adjusting for number of years in practice we found that female and male faculty had similar number of publications $(p=0.50)$. Women were less likely to be on tenure track (adjusted $\mathrm{p}<0.01$ ) and more likely to remain at a lower academic rank despite equivalent number of years in practice (interaction $p<0.001$ ).

\section{Personal life}

Women were more likely than men to be married to or partnered with a professional ( $90 \%$ vs. $37 \%, p<0.001$ for faculty; Table 2$)$. Men and women were equally likely to 
have a physician $(27 \%$ vs. $40 \%, p=0.2)$ or surgeon $(20 \%$ vs. $6 \%, p=0.07)$ spouse or partner. However, it is possible that a statistical difference is not noted due to the limited sample size of this study. Women were more likely to have a spouse employed in a full time position ( $74 \%$ vs. $18 \%, p<0.001)$. Female surgeons were more likely to have delayed childbearing until completion of medical school ( $100 \%$ vs $60 \%, p=0.002)$

or residency ( $81 \%$ vs. $50 \%, p=0.03)$. Female surgeons, thus, had less children $(p=0.04)$ and were more likely to have younger children $(p<0.001)$, even after adjusting for years in practice.

With regards to home-related responsibilities (Figure 1), women faculty surgeons were more likely to be primarily responsible for child care planning $(p<0.001)$, meal planning $(p<0.001)$, grocery shopping $(p<0.001)$, and vacation planning $(p=0.003)$. Male surgeons delegated these tasks to their spouses or partners. Gender neutral responsibilities included financial planning $(p=0.03)$ and monthly bill payment $(p=0.04)$, with these duties being a primary responsibility for male surgeons but a primary responsibility or a shared task between female surgeon and spouse or partner.

\section{Satisfaction scores}

Satisfaction was scored on a Likert-like scale with 1 being unsatisfied, 2 slightly satisfied, 3 satisfied, 4 greatly satisfied, and 5 completely satisfied. Participants were asked to rate satisfaction with their personal life, professional life, and overall work-life balance.

Female faculty surgeons had significantly lower satisfaction in personal life (mean 3.1 vs. $3.7, p=0.02$ ) and work life (mean 2.7 vs. $3.5, p=0.002$ ) compared to male faculty 
surgeons (Table 2). However, there was no significant difference in satisfaction levels between genders in overall work-life balance (mean 2.6 for women vs. 2.9 for men, $\mathrm{p}=0.3)$.

\section{Department of Surgery}

The differences between genders were more pronounced when the Departments of Ophthalmology, Otolaryngology, Orthopedic and Urologic Surgery were excluded (Table 2). Within the Department of the Department of Surgery (Divisions of Abdominal Transplant, Colorectal, Cardiothoracic, Minimally-invasive, Pediatric, Plastic, Surgical Oncology, Trauma, and Vascular Surgery) there was no difference in level of employment, but women faculty were fewer years into practice $(p=0.03)$. After adjusting for years in practice, women faculty had similar number of publications (interaction $\mathrm{p}=0.6$ ) and similar distribution across academic ranks (adjusted $\mathrm{p}=0.1$ ), but were more likely to be on a clinical track (adjusted $\mathrm{p}=0.008$ ) compared to male surgeons. Women faculty were more likely to have a professional $(85 \%$ vs. $26 \%, p<0.001)$ or physician $(54 \%$ vs. $23 \%, p<0.05)$ spouse or partner who was working full time $(83 \%$ vs. $23 \%, p<0.001)$. They were more likely to have less children $(p=0.03)$ and to have delayed child bearing until after medical school (100\% vs. $59 \%, p=0.01)$. Child care planning $(p<0.001)$, meal planning $(p<0.001)$, grocery shopping $(p<0.001)$, and vacation planning $(p=0.05)$ were predominantly performed by female surgeons (Figure 1$)$. Financial planning $(p=0.3)$ and monthly bill $(p=0.8)$ payment were gender-neutral household responsibilities. Personal life, work-life and overall work-life balance satisfaction scores were similar between genders. 


\section{Surgical trainees}

Of the 116 participant trainees, female and male residents were equally as likely to be married (68\% vs. $64 \%, p=0.9$; Table 3$)$. However, female trainees were more likely than male trainees to be married to a professional $(82 \%$ vs.41\%, $p<0.001)$ or physician ( $43 \%$ vs $18 \%, p=0.03$ ), and more likely to be married to someone who is working full time $(93 \%$ vs. $54 \%, p=0.03)$. Female trainees were more likely to not have children $(82 \%$ vs $33 \%, p<0.001)$ and more likely to report the intention of delaying child bearing until after the completion of medical school $(100 \%$ vs. $46 \%, p<0.001)$ or the completion of residency $(77 \%$ vs. $19 \%, p<0.001)$.

Amongst trainees, childcare planning was a shared responsibility between surgeon and spouse for female trainees but primarily a spouse responsibility for male trainees

(Figure 2, $p=0.001$ ). Financial planning was a shared responsibility between female surgical trainees and spouse while it was a primary responsibility for male surgical trainees $(p=0.004)$. Meal planning and grocery shopping were household responsibilities that were evenly divided between self, spouse or both for female trainees, while these household duties were primarily performed by spouses for male trainees $(p<0.001)$. Vacation planning was a gender-neutral household duty amongst trainees $(p=0.2)$

Female trainees reported lower satisfaction with work life compared to their male counterparts (mean 2.9 vs. $3.4, p=0.009$ ). However, there was no statistical significance in satisfaction score between genders amongst trainees in personal life 
(mean 3 for women vs. 3.3 for men, $p=0.1$ ) or overall work-life balance (mean 2.6 for women vs. 2.9 for men, $\mathrm{p}=0.1$ ).

\section{Generational analysis}

We categorized generations of surgeons into trainees, early-career (0-5 years and 6-10 years in practice), mid-career (11-15 years in practice), and late-career surgeons (>15 years in practice). Proportionately, there were more female surgical trainees than faculty ( $42 \%$ vs. $23 \%, p=0.002)$. Additionally, across the generations, there was an increasing trend toward an increasing proportion of female surgeons $(p=0.05$; Table 4). In our study population, the percentage of surgeons in dual-profession $(p=0.7)$ and dual surgeon (interaction $\mathrm{p}=0.9$ ) partnerships remained relatively stable across the generations. However, the change in proportion of dual physician partnerships across the generations was significant $(p=0.002)$. The interaction of these changes with gender was not significant $(p=0.24)$. Similarly, there were no significant trends in surgeon vs. spouse with regards to household chores across the generations. With regards to satisfaction scores, late career surgeons (>15 years in practice) reported higher satisfaction scores in personal life than those in their early/mid-career and in-training surgeons $(p=0.005)$. Mid career surgeons reported lower satisfaction scores in work life (mean 2.9) than surgeons in training (mean 3.2), early-career surgeons (mean 3.2) or those more than 15 years in practice (mean 3.6). However, this was not statistically significant. There was no difference in work-life balance satisfaction scores between trainees, early-, mid-, or late-career surgeons $(p=0.6)$. 


\section{Discussion}

Women are graduating from medical schools at increased proportions ${ }^{1}$. As such, attracting women to surgical specialties is crucial to maintaining a steady surgical work force. Research efforts have focused on medical student perceptions of perceived career satisfaction of female surgeons, the lack of female surgeon role models, and exposure to surgical electives ${ }^{9,10}$. It is clear that in order to attract female medical students into surgery, there need to be more female surgeon role models and more women in leadership roles, with which a network of support can be established. Several studies have documented the glass ceiling effect for women in medicine. Women only account for $17 \%$ of full professors and $12 \%$ of department heads and deans $^{11,12}$. More specific to surgery, only $14-21 \%$ of full time faculty in general surgery residency programs are female ${ }^{11,13}$. Studies on perceived obstacles to academic progression for women list active gender discrimination, social and family issues and lack of effective same-sex mentorship as contributing factors ${ }^{6,11}$.

Confounding this issue is the increase in dual professional and dual physician partnerships. Almost all partnered women in academic medicine are married to another professional who works outside of the home full time. Thirty-one percent of male surgeons' domestic partners compared to $100 \%$ of female surgeons' domestic partners work full time ${ }^{6}$. Concurrently, studies have demonstrated that female surgeons are more likely than male surgeons to have experienced a recent work-home conflict and that work-home conflicts factor in to surgeon burn-out and depression 4,14,15.

Our study evaluated these factors at a large, academic center. Similar to prior reports, we report faculty consisting of $23 \%$ women across all surgical specialties. Women 
surgeons were more likely to be married to a professional working full time ( $80 \%$ vs. $37 \%)$, more likely to have delayed having children ( $100 \%$ vs. $59 \%, p<0.001)$, and more likely to have fewer $(p=0.04)$ and younger-aged children $(p<0.001)$ compared to men surgeons. Professionally, women were more likely than men to be on clinical track ( $80 \%$ vs. $40 \%, p=0.002)$. Finally, in the Department of Surgery, specifically, women surgeons were more likely to be earlier in practice $(p=0.03)$.

This study significantly adds to our understanding of these gender differences as it is the first to delineate the gender disparities of work-life balance that may contribute to academic productivity and, indirectly, impede career development and promotion. We demonstrate that women surgeons are disproportionately more responsible for household functions than male surgeons despite a higher proportion of female surgeons being married to a full time working professional than male surgeons. We also evaluated these gender differences amongst surgical trainees. Despite a higher proportion of women amongst trainees than faculty, the gender differences in life partnerships and allocation of household responsibilities exist. Thus, even early on, at the trainee level, gender differences may be biasing women surgeons away from an academic career or toward a clinical track in an academic career.

Lastly, in reviewing differences amongst the various generations of surgeons, our study demonstrated that the proportion of female surgeons is increasing. While we did not find that the proportion of dual profession/dual physician/dual surgeon partnerships is increasing across the generations in our study, this trend is true nationally regardless of gender ${ }^{15,16}$. As a result, male surgeons likely are progressively playing a larger role in household responsibilities. Therefore, the concept of work-home conflicts contributing 
to surgeon burn out, delays in academic progress and attrition now is becoming a gender-neutral concern. As stated by Colleti, et al, "an increasing number of men are married to professionals... and increasingly, all faculty must balance their personal and academic responsibilities" ${ }^{6}$. It is promising, however, that the satisfaction scores for overall work-life balance were reasonable and the same for both men and women. In an attempt to support female faculty for improved recruitment and retention, several institutions have implemented policy changes. The concept of "clock stopping" for tenure track physicians has been implemented at the majority of Universities ${ }^{17,18}$. While the intention of this policy was to be supportive of women faculty, delaying promotion following an already extended training time period can be construed as punitive, particularly for faculty who are diligently working both at work and at home. Fried, et al published their report of changes_-including education of faculty, faculty development and mentoring, awards_-implemented at Johns Hopkins University ${ }^{19}$. These changes resulted in increased retention and promotion of female faculty. Similarly, Stanford University implemented institutional changes with the intent of recruiting and retaining female faculty ${ }^{20}$. The interventions implemented resulted in a $74 \%$ increase in female faculty and $66 \%$ increase in the successful promotion of female faculty-twice the increase of national average.

While these studies demonstrated excellent success in improving the recruitment and retention of women in academic medicine through work-related interventions, the interventions do not alleviate the competitive stressors from personal life that affect women more so than men. More creative and flexible strategies or policies need to be implemented ${ }^{21}$. Home-life directed interventions (such as on-site daycare, back-up child 
care, in-house nanny recruitment/referral services, etc) may alleviate this stressor and result in decreased surgeon burn-out, improved retention, and should be considered by academic institutions and hospital health care systems. Furthermore, more flexible policies on promotion and tenure-such as factoring in the challenges of dual profession/dual physician/dual surgeon partnerships during the promotion process ("acknowledge and value the whole person beyond the surgeon"10), or the ability to maintain tenure despite a part time status—may similarly result in successful career development, promotion and faculty retention ${ }^{18}$. Lastly, making these home-life directed interventions/resources available to trainees may equalize the gender differences at the training level and result in an increased proportion of female surgeons interested in pursuing a career in academic surgery on tenure track. We implore surgical leaders to institute some of these flexible and facilitating policies, in an attempt to improve the work-life balance for female surgeons and for surgeons in dual-professional partnerships.

Our study has several limitations inherent to all survey-based studies. We acknowledge that this is one snapshot view of one single academic institution. The male/female ratio of our faculty and trainees are comparable to national data ${ }^{2,13}$. We also hope to carry this work forward with a national survey including surgeons in both the academic and non-academic realm. The results were subject to biases based on the voluntary nature of survey response. With an $80 \%$ response rate from faculty and $95 \%$ response rate from trainees, we feel that this bias is limited. Finally, the results are subject to reporting bias, which is a limitation of any survey study. 
In summary, we report gender and generational differences in factors that may play a significant role in the recruitment, satisfaction and retention of female and male surgeons, alike, which likely will have an effect on the future surgical work force.

\section{Conclusions}

The work milieu and the work force are rapidly evolving. The proportion of women surgeons is steadily increasing, as is the proportion of surgeons (female and male) in

dual-professional households. Attention to this change, as well as to competing interests, may play a role in mitigating surgeon burn out and improving work-life balance satisfaction. Implementation of research-driven changes in policies that facilitate successful career development and promotion will aid in equalizing gender disparities, lead to improvement in recruitment, and result in retention of the current and subsequent generations of surgeons. 


\section{References}

1. AAMC.org. FACTS: Applicants, Matriculants, Enrollment, Graduates, M.D.-Ph.D., and Residency Applicants Data.

\section{https://www.aamc.org/download/321442/data/factstablea1.pdf. Accessed} 2/7/2017.

2. Davis EC, Risucci DA, Blair PG, Sachdeva AK. Women in surgery residency programs: evolving trends from a national perspective. J Am Coll Surg. 2011;212(3):320-326.

3. Staiger DO, Marshall SM, Goodman DC, Auerbach DI, Buerhaus PI. Association Between Having a Highly Educated Spouse and Physician Practice in Rural Underserved Areas. JAMA. 2016;315(9):939-941.

4. Dyrbye LN, Shanafelt TD, Balch CM, Satele D, Sloan J, Freischlag J. Relationship between work-home conflicts and burnout among American surgeons: a comparison by sex. Arch Surg. 2011;146(2):211-217.

5. Dresler CM, Padgett DL, MacKinnon SE, Patterson GA. Experiences of women in cardiothoracic surgery. A gender comparison. Arch Surg. 1996;131(11):11281134; discussion 1135.

6. Colletti LM, Mulholland MW, Sonnad SS. Perceived obstacles to career success for women in academic surgery. Arch Surg. 2000;135(8):972-977.

7. Survey Monkey, Inc. San Mateo, California, USA. http://www.surveymonkey.com. Accessed 2016.

8. Sullivan GM, Artino AR, Jr. Analyzing and interpreting data from likert-type scales. J Grad Med Educ. 2013;5(4):541-542. 
9. Baxter N, Cohen R, McLeod R. The impact of gender on the choice of surgery as a career. Am J Surg. 1996;172(4):373-376.

10. Ahmadiyeh N, Cho NL, Kellogg KC, et al. Career satisfaction of women in surgery: perceptions, factors, and strategies. J Am Coll Surg. 2010;210(1):23-28.

11. Cochran A, Hauschild T, Elder WB, Neumayer LA, Brasel KJ, Crandall ML. Perceived gender-based barriers to careers in academic surgery. Am J Surg. 2013;206(2):263-268.

12. Sexton KW, Hocking KM, Wise $\mathrm{E}$, et al. Women in academic surgery: the pipeline is busted. J Surg Educ. 2012;69(1):84-90.

13. Valsangkar N, Fecher AM, Rozycki GS, et al. Understanding the Barriers to Hiring and Promoting Women in Surgical Subspecialties. J Am Coll Surg. 2016;223(2):387-398 e382.

14. Dyrbye LN, Freischlag J, Kaups KL, et al. Work-home conflicts have a substantial impact on career decisions that affect the adequacy of the surgical workforce. Arch Surg. 2012;147(10):933-939.

15. Dyrbye LN, Shanafelt TD, Balch CM, Satele D, Freischlag J. Physicians married or partnered to physicians: a comparative study in the American College of Surgeons. J Am Coll Surg. 2010;211(5):663-671.

16. Fletcher RH, Fletcher SW. Here come the couples. Ann Intern Med. 1993;119(7 Pt 1):628-630.

17. Osborn EH, Ernster VL, Martin JB. Women's attitudes toward careers in academic medicine at the University of California, San Francisco. Acad Med. 1992;67(1):59-62. 
18. Bunton SA, Corrice AM. Evolving workplace flexibility for U.S. medical school tenure-track faculty. Acad Med. 2011;86(4):481-485.

19. Fried LP, Francomano CA, MacDonald SM, et al. Career development for women in academic medicine: Multiple interventions in a department of medicine. JAMA. 1996;276(11):898-905.

20. Valantine HA, Grewal D, Ku MC, et al. The gender gap in academic medicine: comparing results from a multifaceted intervention for stanford faculty to peer and national cohorts. Acad Med. 2014;89(6):904-911.

21. Bhattacharjee Y. Academic careers. Family matters: stopping tenure clock may not be enough. Science. 2004;306(5704):2031-2033. 
Figure 1. Graphical representation of division of household chores between faculty surgeon and spouse/partner. Survey response options were self $>60 \%$ of time, spouse/partner $>60 \%$ of time, or both $(40-60 \%$ split).

Figure 2. Graphical representation of division of household chores between surgical trainees and spouse/partner. Survey response options were self $>60 \%$ of time, spouse/partner $>60 \%$ of time, or both (40-60\% split). 
Appendix 1. Faculty survey.

Appendix 2. Gender differences in division of household responsibilities amongst surgical faculty and trainees. Division of household responsibilities were self ( $>60 \%$ of time), spouse/partner ( $>60 \%$ of time) or both $(40-60 \%$ split between surgeon and spouse).

Acknowledgements

Much gratitude to EPC not only for being the inspiration for this study (-)), but also for being the anchor and biggest proponent of DPC's career.

Disclosures

The authors have nothing to disclose. 
Table 1. Participant demographics.

\begin{tabular}{|c|c|c|c|}
\hline & Faculty N (\%) & Resident N (\%) & p-value \\
\hline \multirow{2}{*}{$\begin{array}{r}\text { Surgical Specialty: } \\
\text { General Surgery }\end{array}$} & $\mathrm{N}=119$ & $\mathrm{~N}=116$ & \multirow[t]{7}{*}{0.38} \\
\hline & $66(55.5)$ & $76(65.5)$ & \\
\hline Neurosurgery & $9(7.6)$ & $5(4.3)$ & \\
\hline Ophthalmology & $7(5.9)$ & $7(6.0)$ & \\
\hline Orthopedic Surgery & $10(8.4)$ & $12(10.3)$ & \\
\hline Otolaryngology, Head and Neck Surgery & $12(10.1)$ & $9(7.8)$ & \\
\hline \multirow{2}{*}{$\begin{array}{l}\text { Urology } \\
\text { General Surgery Subspecialty: }\end{array}$} & $15(12.6)$ & $7(6.0)$ & \\
\hline & $\mathrm{N}=59$ & $\mathrm{~N}=50$ & \multirow[t]{10}{*}{0.29} \\
\hline Abdominal transplant & $3(5.1)$ & $5(10.0)$ & \\
\hline Cardiothoracic surgery (including CT transplant) & $9(15.3)$ & $9(18.0)$ & \\
\hline Colorectal surgery & $4(6.8)$ & $7(14.0)$ & \\
\hline Minimally invasive and/or bariatric surgery & $4(6.8)$ & $2(4.0)$ & \\
\hline Pediatric Surgery & $1(1.7)$ & $2(4.0)$ & \\
\hline Plastic surgery & $4(6.8)$ & $6(12.0)$ & \\
\hline $\begin{array}{l}\text { Surgical oncology (breast, endocrine, } \\
\text { hepaticopancreaticobiliary) }\end{array}$ & $14(23.7)$ & $7(14.0)$ & \\
\hline Trauma \& critical care & $15(25.4)$ & $5(10.0)$ & \\
\hline \multirow{3}{*}{$\begin{array}{l}\text { Vascular surgery } \\
\text { Female }\end{array}$} & $5(8.5)$ & $7(14.0)$ & \\
\hline & $\mathrm{N}=119$ & $\mathrm{~N}=115$ & \multirow[t]{2}{*}{$<0.01$} \\
\hline & $28(23.5)$ & $48(41.7)$ & \\
\hline \multirow[t]{2}{*}{ Married } & $\mathrm{N}=119$ & $\mathrm{~N}=103$ & \multirow[t]{3}{*}{$<0.01$} \\
\hline & $104(87.4)$ & $68(66.0)$ & \\
\hline \multirow{3}{*}{$\begin{array}{l}\text { Have Children: } \\
\text { Overall }\end{array}$} & $\mathrm{N}=119$ & $\mathrm{~N}=116$ & \\
\hline & $103(86.6)$ & $31(26.7)$ & \multirow[t]{2}{*}{$<0.01$} \\
\hline & $\mathrm{N}=104$ & $\mathrm{~N}=68$ & \\
\hline Those Married & $97(93.3)$ & $31(45.6)$ & $<0.01$ \\
\hline
\end{tabular}


Table 2. Faculty gender differences in employment, domestic choices, and satisfaction scores for all participants and the Department of Surgery.

\begin{tabular}{|c|c|c|c|c|c|c|}
\hline & Overall & & & Department of & urgery & \multirow{3}{*}{$\begin{array}{l}\text { p-value } \\
0.03\end{array}$} \\
\hline \multirow[b]{2}{*}{ Years in Practice: } & Female N (\%) & Male N (\%) & \multirow{2}{*}{$\begin{array}{c}\text { p-value } \\
0.050\end{array}$} & Female N (\%) & Male N (\%) & \\
\hline & $\mathrm{N}=28$ & $N=91$ & & $\mathrm{~N}=17$ & $N=49$ & \\
\hline $0-5$ & $10(35.7)$ & $23(25.3)$ & & $8(47.1)$ & $10(20.4)$ & \\
\hline $6-10$ & 8 (28.9) & $14(15.4)$ & & $4(23.5)$ & $6(12.2)$ & \\
\hline $11-15$ & 5 (17.9) & $13(14.3)$ & & $2(11.8)$ & $8(16.3)$ & \\
\hline$>15$ & 5 (17.9) & $41(45.1)$ & & $3(17.7)$ & $25(51.0)$ & \\
\hline \multirow{2}{*}{$\begin{array}{l}\text { Level of Employment: } \\
\qquad<0.5 \text { FTE }\end{array}$} & $\mathrm{N}=28$ & $\mathrm{~N}=90$ & 0.384 & $\mathrm{~N}=17$ & $N=48$ & 0.52 \\
\hline & $1(3.6)$ & $0(0.0)$ & & $1(5.9)$ & $0(0.0)$ & \\
\hline 0.5-0.75 FTE & $1(3.6)$ & $2(2.2)$ & & $0(0.0)$ & $1(2.1)$ & \\
\hline$>0.75$ to $<1 \mathrm{FTE}$ & $2(7.1)$ & $7(7.8)$ & & $1(5.9)$ & $4(8.3)$ & \\
\hline 1 FTE & $24(85.7)$ & $81(90.0)$ & & $15(88.2)$ & $43(89.6)$ & \\
\hline Academic Track: & $\mathrm{N}=20$ & $\mathrm{~N}=63$ & 0.002 & $\mathrm{~N}=13$ & $N=32$ & $<0.01$ \\
\hline Clinical & $16(80.0)$ & $25(39.7)$ & & $11(84.6)$ & $9(28.1)$ & \\
\hline Tenure & $4(20.0)$ & $38(60.3)$ & & $2(15.4)$ & $23(71.9)$ & \\
\hline Academic Rank: & $\mathrm{N}=27$ & $\mathrm{~N}=89$ & 0.117 & $\mathrm{~N}=16$ & $\mathrm{~N}=47$ & 0.01 \\
\hline Assistant Professor & $19(70.4)$ & $43(48.3)$ & & $12(75.0)$ & $15(31.9)$ & \\
\hline Associate Professor & $4(14.8)$ & $18(20.2)$ & & $2(12.5)$ & $13(27.7)$ & \\
\hline Professor & $4(14.8)$ & $28(31.5)$ & & $2(12.5)$ & $19(40.4)$ & \\
\hline \multirow[t]{2}{*}{ Married } & $\mathrm{N}=28$ & $\mathrm{~N}=91$ & & $\mathrm{~N}=17$ & $N=49$ & \\
\hline & $20(71.4)$ & $84(92.3)$ & 0.005 & $13(76.5)$ & $43(87.8)$ & 0.43 \\
\hline Spouse Occupation: & $\mathrm{N}=20$ & $\mathrm{~N}=83$ & & $\mathrm{~N}=13$ & $\mathrm{~N}=43$ & \\
\hline Professional & $16(90.0)$ & $31(37.4)$ & $<0.001$ & $11(84.6)$ & $11(25.6)$ & $<0.01$ \\
\hline Physician & $8(40.0)$ & $22(26.5)$ & 0.233 & 7 (53.9) & $10(23.3)$ & 0.05 \\
\hline Surgeon & $4(20.0)$ & $5(6.0)$ & 0.069 & $4(30.8)$ & $5(11.6)$ & 0.19 \\
\hline $\begin{array}{l}\text { Surgeon } \\
\text { Spouse Level of } \\
\text { Employment: }\end{array}$ & $\mathrm{N}=19$ & $\mathrm{~N}=78$ & $<0.001$ & $\mathrm{~N}=12$ & $\mathrm{~N}=35$ & $<0.01$ \\
\hline Homemaker & $3(15.8)$ & $31(42.5)$ & & $2(16.7)$ & $15(42.9)$ & \\
\hline Part Time & $2(10.5)$ & $29(39.7)$ & & $0(0.0)$ & $12(34.3)$ & \\
\hline
\end{tabular}




\begin{tabular}{|c|c|c|c|c|c|c|}
\hline \multirow{3}{*}{$\begin{array}{c}\text { Full Time } \\
\text { Have Children }\end{array}$} & $14(73.7)$ & $13(17.8)$ & \multirow{5}{*}{0.6173} & $10(83.3)$ & 8 (22.9) & \multirow[b]{3}{*}{1.000} \\
\hline & $\mathrm{N}=\mathbf{2 0}$ & $N=84$ & & $\mathrm{~N}=13$ & $N=43$ & \\
\hline & $18(90.0)$ & 79 (94.1) & & $12(92.3)$ & $40(93.0)$ & \\
\hline \multirow{3}{*}{$\begin{array}{l}\text { Delayed Having } \\
\text { Children: } \\
\text { Complete Medical } \\
\text { School }\end{array}$} & & & & & & \\
\hline & $\mathrm{N}=15$ & $N=37$ & & $\mathrm{~N}=11$ & $\mathrm{~N}=17$ & \multirow{3}{*}{0.01} \\
\hline & $15(100.0)$ & $22(59.5)$ & \multirow[t]{2}{*}{0.002} & $11(100.0)$ & $10(58.8)$ & \\
\hline \multirow[t]{2}{*}{ Complete Residency } & $N=16$ & $N=41$ & & $\mathrm{~N}=12$ & $\mathrm{~N}=19$ & \\
\hline & $13(81.3)$ & $20(48.8)$ & \multirow[t]{2}{*}{0.030} & $9(75.0)$ & $8(42.1)$ & \multirow[t]{2}{*}{0.07} \\
\hline \multirow[t]{2}{*}{ Start as Faculty } & $N=16$ & $N=35$ & & $\mathrm{~N}=11$ & $\mathrm{~N}=17$ & \\
\hline & $7(43.8)$ & $6(17.1)$ & \multirow[t]{2}{*}{0.080} & $3(27.3)$ & $4(23.5)$ & \multirow[t]{2}{*}{1.000} \\
\hline $\begin{array}{l}\text { Level of Satisfaction } \\
\text { with work: }\end{array}$ & $N=27$ & $\mathrm{~N}=88$ & & $\mathrm{~N}=17$ & $\mathrm{~N}=46$ & \\
\hline Personal Life & $3.11(1.31)$ & $3.70(1.02)$ & 0.015 & $3.35(1.17)$ & $3.57(1.09)$ & 0.50 \\
\hline Work Life & $2.74(1.20)$ & $3.47(1.02)$ & 0.002 & $2.82(1.29)$ & $3.37(0.93)$ & 0.07 \\
\hline Balance & $2.63(1.36)$ & $2.93(1.18)$ & 0.266 & $2.76(1.44)$ & 2.84 (1.19) & 0.82 \\
\hline
\end{tabular}


Table 3. Gender differences in surgical trainees.

\begin{tabular}{|c|c|c|c|}
\hline & Female N (\%) & Male N (\%) & p-value \\
\hline \multirow[t]{2}{*}{ Married } & $\mathrm{N}=41$ & $N=61$ & \multirow[t]{3}{*}{0.90} \\
\hline & $28(68.3)$ & $39(63.9)$ & \\
\hline Spouse Occupation: & $\mathrm{N}=28$ & $\mathrm{~N}=39$ & \\
\hline Professional & $23(82.1)$ & $16(41.0)$ & $<0.01$ \\
\hline Physician & $12(42.9)$ & $7(18.0)$ & 0.03 \\
\hline Surgeon & $5(17.9)$ & $1(2.6)$ & 0.08 \\
\hline \multirow{2}{*}{$\begin{array}{l}\text { Spouse Level of Employment: } \\
\text { Full Time }\end{array}$} & $\mathrm{N}=28$ & $N=37$ & \multirow[t]{4}{*}{$<0.01$} \\
\hline & $26(92.9)$ & $20(54.1)$ & \\
\hline Part Time & $1(3.6)$ & $10(27.0)$ & \\
\hline Homemaker & $1(3.6)$ & $7(18.9)$ & \\
\hline \multirow[t]{2}{*}{ Have Children } & $\mathrm{N}=28$ & $N=39$ & \multirow[t]{2}{*}{$<0.01$} \\
\hline & $5(17.9)$ & $26(66.7)$ & \\
\hline \multirow[t]{2}{*}{ Number of Children: } & $\mathrm{N}=\mathbf{2 8}$ & $\mathrm{N}=39$ & \multirow[t]{4}{*}{$<0.01$} \\
\hline & $23(82.1)$ & $13(33.3)$ & \\
\hline $1-2$ & $5(17.9)$ & $21(53.9)$ & \\
\hline$\geq 3$ & $0(0.0)$ & $5(12.8)$ & \\
\hline \multicolumn{3}{|l|}{ Delayed Having Children: } & \\
\hline \multirow[t]{2}{*}{ Complete Medical School } & $\mathrm{N}=15$ & $\mathrm{~N}=22$ & \\
\hline & $15(100.0)$ & $10(45.5)$ & \multirow[t]{2}{*}{$<0.01$} \\
\hline \multirow[t]{2}{*}{ Start Research } & $\mathrm{N}=12$ & $\mathrm{~N}=24$ & \\
\hline & $6(50.0)$ & $5(20.8)$ & \multirow[t]{2}{*}{0.12} \\
\hline \multirow[t]{2}{*}{ Complete Residency } & $\mathrm{N}=17$ & $\mathrm{~N}=26$ & \\
\hline & $13(76.5)$ & $5(19.2)$ & \multirow[t]{2}{*}{$<0.01$} \\
\hline $\begin{array}{l}\text { Level of Satisfaction with } \\
\text { work: }\end{array}$ & $\mathrm{N}=39$ & $N=58$ & \\
\hline Personal Life & $2.97(1.16)$ & $3.29(0.96)$ & 0.14 \\
\hline Work Life & $2.92(0.81)$ & $3.41(0.94)$ & $<0.01$ \\
\hline Balance & $2.58(0.98)$ & $2.91(1.00)$ & 0.11 \\
\hline
\end{tabular}


Table 4. Generational analysis of proportion of women surgeons, life partnership patterns and satisfaction score.

\begin{tabular}{|c|c|c|c|c|c|c|}
\hline & Residents & Faculty $0-5$ & Faculty 6-10 & Faculty 11-15 & Faculty >15 & p-value \\
\hline \multirow{2}{*}{$\begin{array}{l}\text { Gender } \\
\text { Female }\end{array}$} & $\mathrm{N}=\mathbf{1 1 5}$ & $\mathrm{N}=33$ & $\mathrm{~N}=22$ & $\mathrm{~N}=18$ & $\mathrm{~N}=46$ & \multirow[t]{4}{*}{$<0.01$} \\
\hline & $48(41.7)$ & $10(30.3)$ & $8(36.3)$ & $5(27.8)$ & $5(10.9)$ & \\
\hline Male & $67(58.3)$ & $23(69.7)$ & $14(63.6)$ & $13(72.2)$ & 41(89.1) & \\
\hline \multirow[t]{2}{*}{ Married } & $\mathrm{N}=103$ & $N=33$ & $\mathrm{~N}=22$ & $\mathrm{~N}=18$ & $\mathrm{~N}=46$ & \\
\hline & $68(66.0)$ & $27(81.8)$ & $22(100.0)$ & $13(72.2)$ & $42(91.3)$ & \multirow[t]{2}{*}{$<0.01$} \\
\hline \multirow[t]{2}{*}{ Have Children } & $\mathrm{N}=68$ & $\mathrm{~N}=27$ & $\mathrm{~N}=22$ & $\mathrm{~N}=13$ & $\mathrm{~N}=42$ & \\
\hline & $31(45.6)$ & $25(92.6)$ & $22(100.0)$ & $12(92.3)$ & $38(90.5)$ & \multirow[t]{2}{*}{$<0.01$} \\
\hline \multirow[t]{2}{*}{ Married to Professional } & $\mathrm{N}=68$ & $\mathrm{~N}=27$ & $\mathrm{~N}=22$ & $\mathrm{~N}=13$ & $\mathrm{~N}=41$ & \\
\hline & $40(58.8)$ & $14(51.9)$ & $12(54.6)$ & $8(61.5)$ & $13(31.7)$ & \multirow[t]{2}{*}{0.08} \\
\hline \multirow[t]{2}{*}{ Married to Physician } & $N=68$ & $N=27$ & $\mathrm{~N}=22$ & $\mathrm{~N}=13$ & $N=41$ & \\
\hline & $19(27.9)$ & $8(29.6)$ & $10(45.5)$ & $8(61.5)$ & $4(9.8)$ & \multirow[t]{2}{*}{$<0.01$} \\
\hline \multirow[t]{2}{*}{ Married to Surgeon } & $N=68$ & $N=27$ & $\mathrm{~N}=22$ & $\mathrm{~N}=13$ & $N=41$ & \\
\hline & $6(8.8)$ & $2(7.4)$ & $2(9.1)$ & $2(15.4)$ & $3(7.3)$ & \multirow[t]{2}{*}{0.90} \\
\hline $\begin{array}{l}\text { Level of Satisfaction } \\
\text { with work: }\end{array}$ & $\mathrm{N}=98$ & $\mathrm{~N}=32$ & $\mathrm{~N}=22$ & $\mathrm{~N}=17$ & $N=44$ & \\
\hline Personal Life & $3.14(1.06)$ & 3.34 (1.21) & $3.36(1.00)$ & $3.35(1.00)$ & $3.91(1.10)$ & $<0.01$ \\
\hline Work Life & $3.21(0.91)$ & 3.28 (1.11) & $3.09(0.87)$ & $2.88(1.11)$ & $3.57(1.15)$ & 0.12 \\
\hline Balance & $2.76(1.01)$ & $2.87(1.38)$ & $2.59(0.85)$ & $2.76(1.09)$ & $3.02(1.32)$ & 0.62 \\
\hline
\end{tabular}


Monthly bill payment

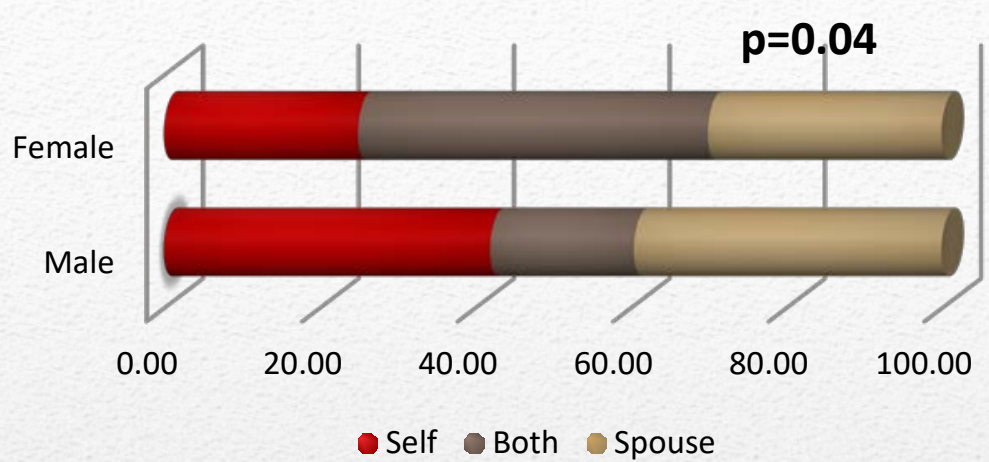

Financial planning

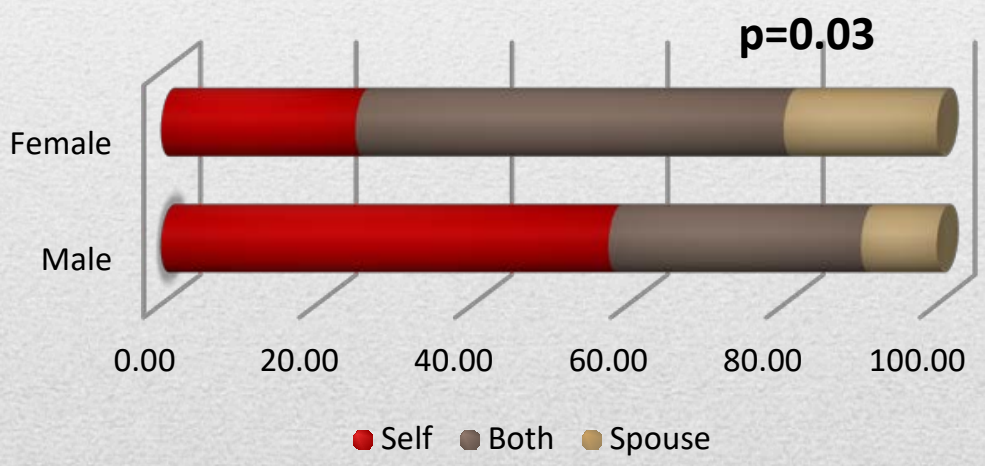

Vacation planning

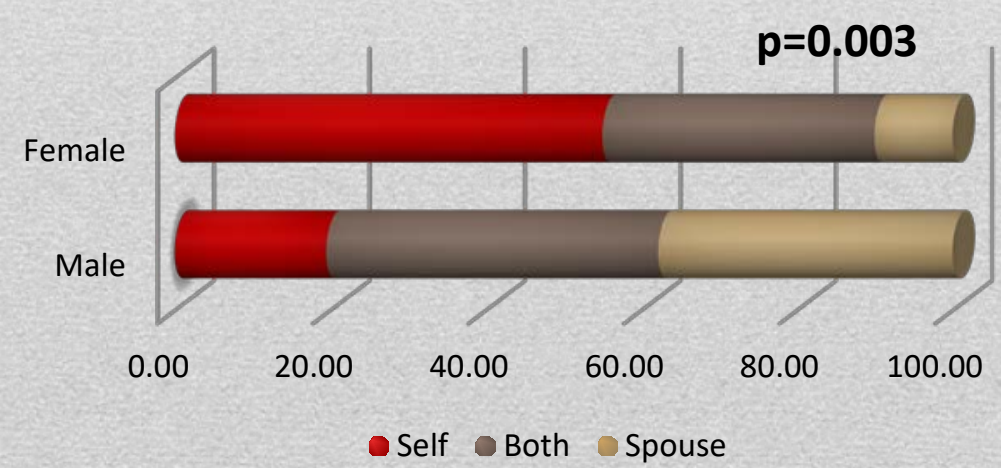

Child care planning

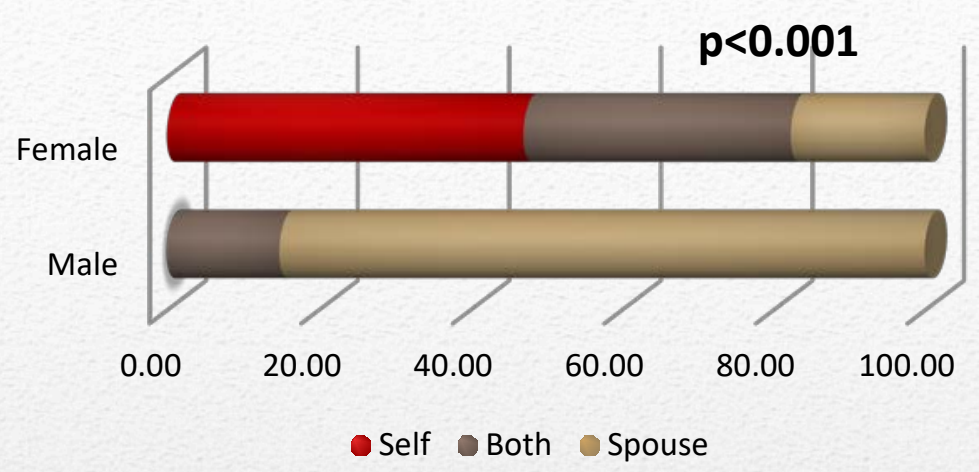

Meal planning

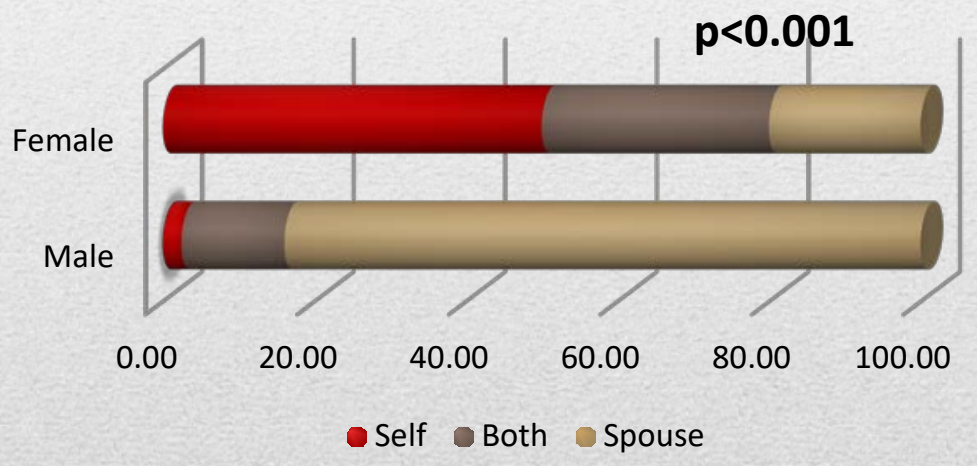

Grocery shopping

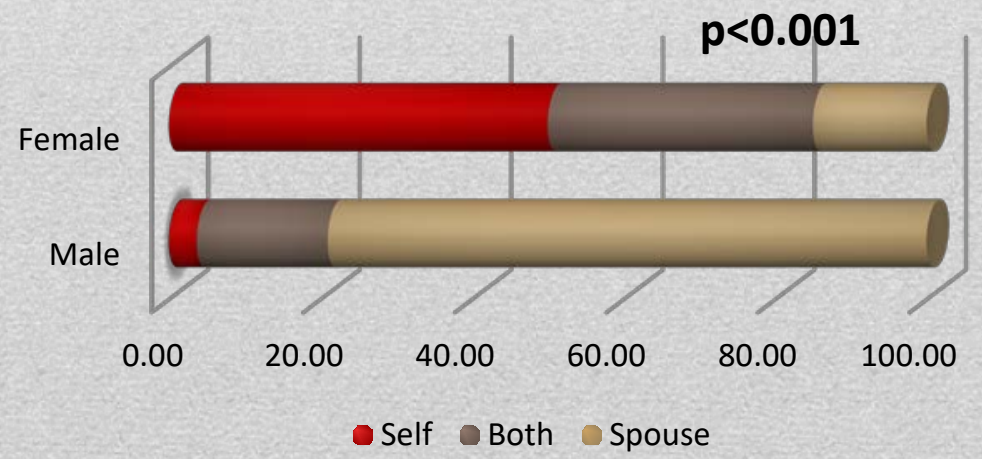


Monthly bill payment

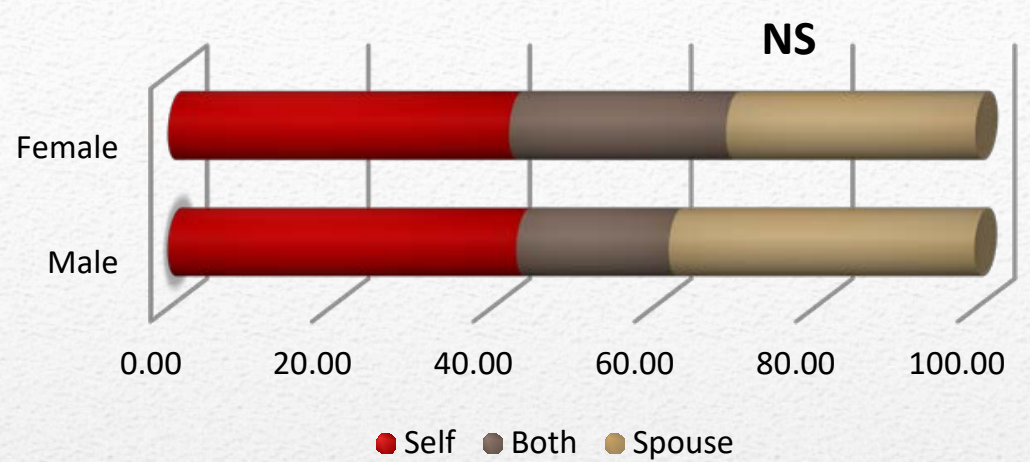

Financial planning

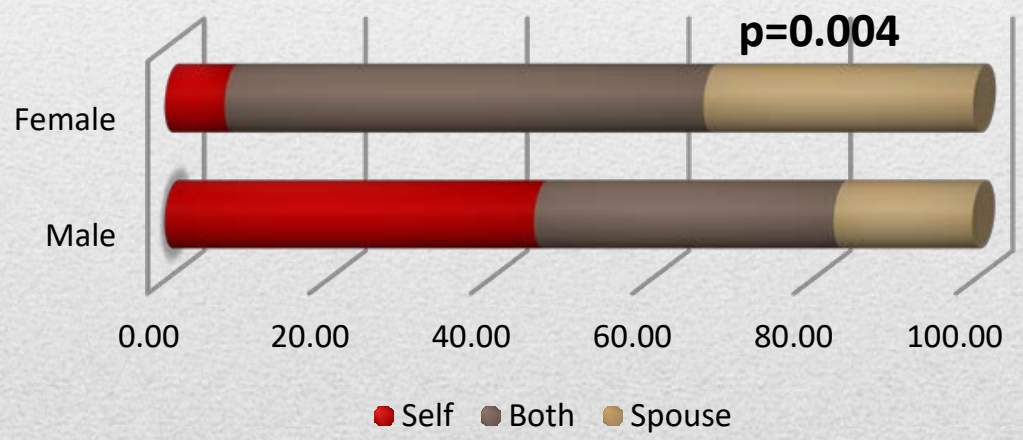

Vacation planning

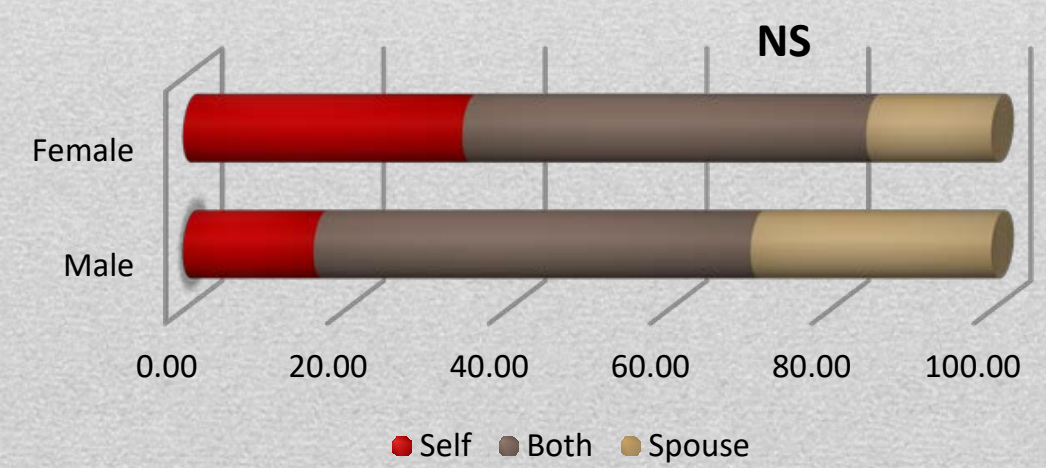

Child care planning

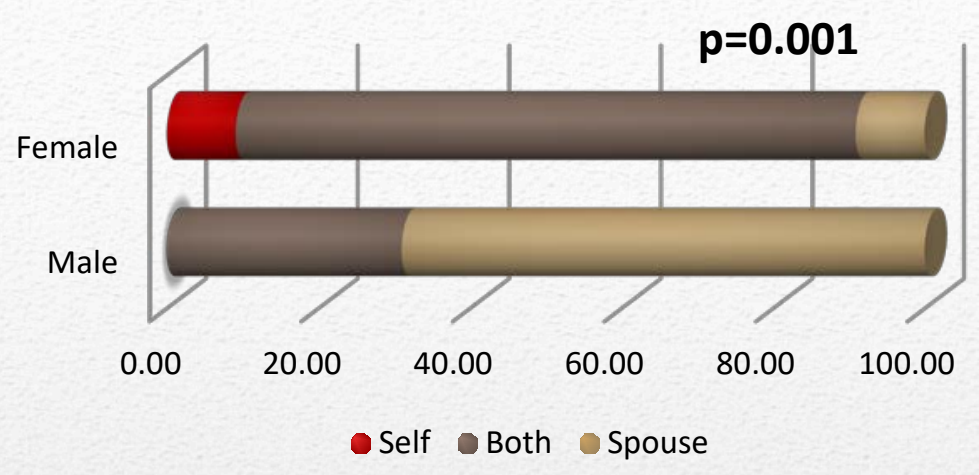

Meal planning

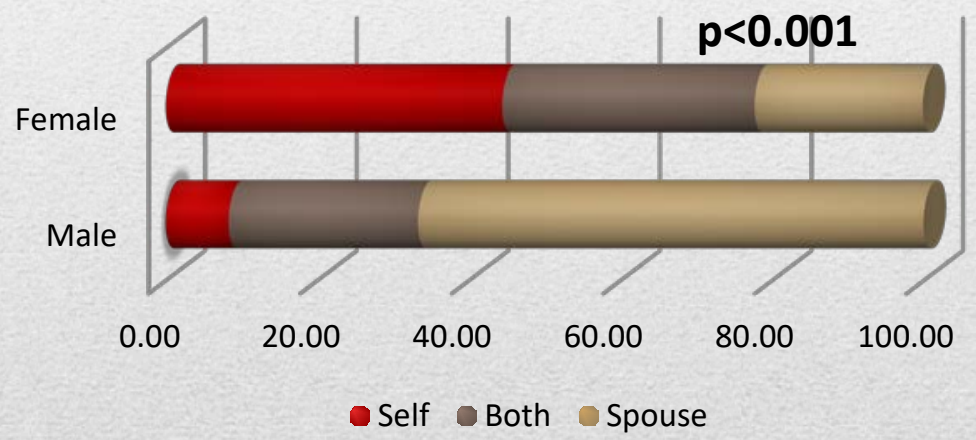

Grocery shopping

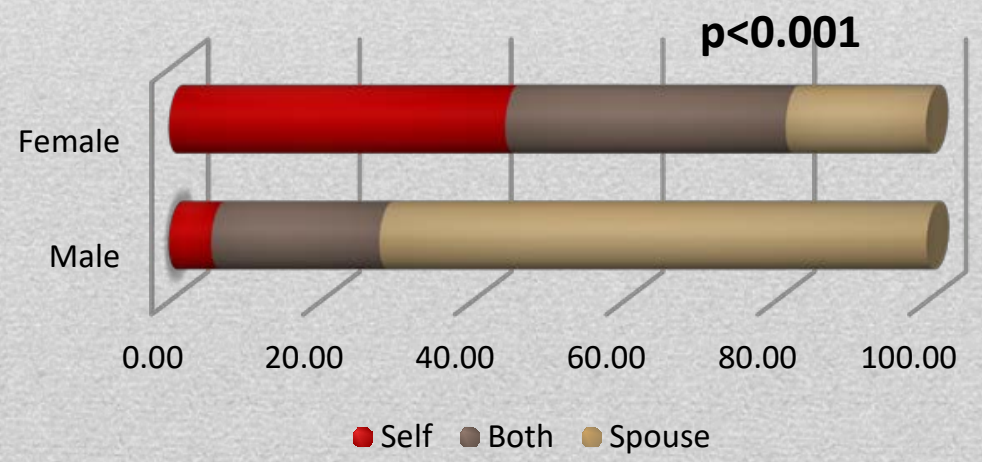

